Check for updates

Cite this: RSC Adv., 2017, 7, 34118

\section{Amphiphilic silane modified multifunctional nanoparticles for ratiometric oxygen sensing †}

\author{
Yanxia Lin,\$ Hongwei Xu, \$ Biao Dong, D * Xueke Sun, Chunhe Li, Jianing Li, Lin Xu, \\ Xue Bai and Hongwei Song (iD
}

Precise detection of dissolved oxygen (DO) at the cellular level plays a pivotal role in the diagnosis of many diseases and intraoperative observation. In this work, we designed a ratiometric fluorescence DO sensing probe based on efficient energy transfer at long wavelength excitation. The oxygen probe Pt(॥)-mesotetra(pentafluorophenyl)porphine (PtTFPP), the reference dye Coumarin 6 (C6) and $\mathrm{Fe}_{3} \mathrm{O}_{4} \mathrm{NPs}$ were encapsulated by amphiphilic silane at room temperature. The results indicate the important role of $\mathrm{C} 6$ molecules in the composite, serving as not only the ratiometric reference probe, but also the sensitizer of efficient energy transfer. The emission from PtTFPP can be greatly enhanced by 20 times based on the energy transfer pathway from C6 relative to that with the intrinsic excitation wavelength. DO sensing was successfully carried out based on ratiometric fluorescence in the imitation environment and at the cellular level under a confocal microscope. In addition, the cell magnetic separation function makes the composite possess great potential in DO sensing related medical applications.
Received 10th May 2017

Accepted 27th June 2017

DOI: $10.1039 / \mathrm{c} 7 \mathrm{ra05282k}$

rsc.li/rsc-advances time. ${ }^{26}$ Therefore, the ratiometric oxygen sensors are designed by incorporating reference-probe dual-dye systems into an inert matrix in the form of sensor strips, ${ }^{27}$ films, ${ }^{28}$ microparticles $^{29}$ and nanoparticles (NPs), ${ }^{\mathbf{2 1 , 2 9 - 3 1}}$ where the oxygen sensing can be obtained by ratiometric approaches, i.e. simultaneously detecting two signals by a single excitation wavelength. ${ }^{26} \mathrm{~K}$. A. Van Houten et al. ${ }^{32}$ first developed an oxygen-sensitive dyes, possessing two distinct emission peaks with differing sensitivity to oxygen quenching, platinum 1,2-enedithiolates and further applied it in the DO sensing by a ratiometric method. After that, the ratiometric detection makes a rapid progress. Jason $\mathrm{McNeill}$ and $\mathrm{Wu}$ et $a{ }^{.33}$ designed a novel nanoparticle architecture for ratiometric fluorescence oxygen sensing that consisted of $\mathrm{p}$ conjugated polymer molecules doped with an oxygen-sensitive dye. Besides, they observed the efficient energy transfer from the polymer to phosphorescent dye upon light excitation, resulting in bright phosphorescence. Peng and Wolfbeis et al. ${ }^{34}$ further developed a method to assess tumor mitochondrial dysfunction with three phosphorescent nanosensors, which responded to the oxygen among the subcellular organelles.

As the in-depth study, to meet the requirements of the clinic applications, the DO sensing probe should have some features on consideration of low toxicity, high efficiency and sensitivity in the live cell or tissue environments, such as long wavelength excitation, well designed combination of oxygen probe and reference-probe. In addition, the multifunction design of the probe also becomes an important issue for the theranostic applications.

In this work, we designed a multifunctional oxygen probes based on amphiphilic silane modification method we recently 

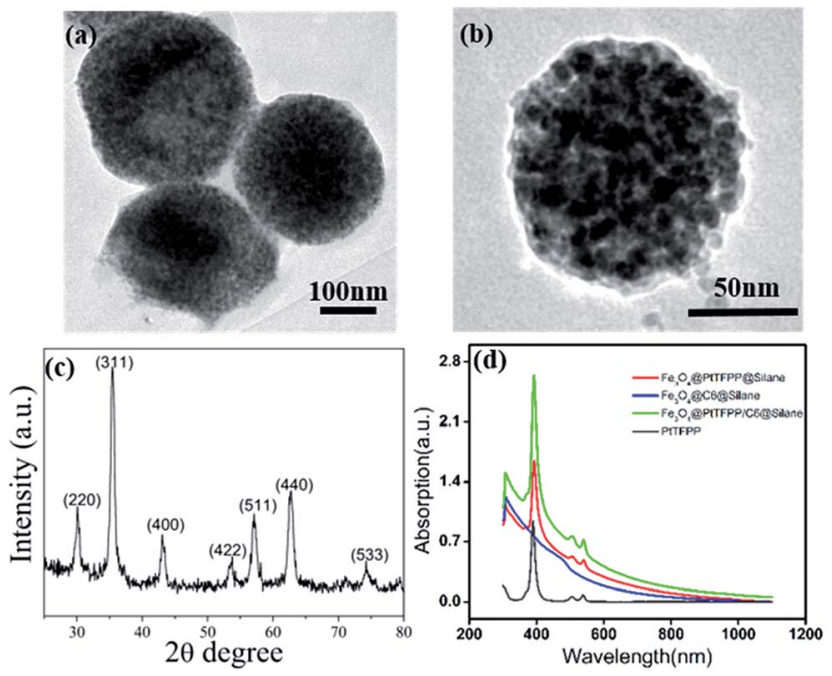

Fig. 1 (a) TEM images of (a) $\mathrm{Fe}_{3} \mathrm{O}_{4}$ (aPtTFPP/C6 a silane NPs and (b) one single $\mathrm{Fe}_{3} \mathrm{O}_{4}$ aPtTFPP/C6 a silane NP. (c) The XRD pattern of $\mathrm{Fe}_{3} \mathrm{O}_{4}$ NPs accorded with JCPDS 6563107. (d) UV-Vis absorption spectra of $\mathrm{Fe}_{3} \mathrm{O}_{4} @$ PtTFPP@silane, $\mathrm{Fe}_{3} \mathrm{O}_{4} \mathrm{aC} 6$ @ silane, $\mathrm{Fe}_{3} \mathrm{O}_{4} @$ aPtTFPP/C6@asilane and pure PtTFPP.

developed for multifunctional platform, which can encapsulate the hydrophobic functional molecules by hydrophobic interaction, while the outside hydrophilic hydroxy can facilitate the bioapplications. The oxygen probe $\mathrm{Pt}(\mathrm{II})$-meso-tetra(pentafluorophenyl)porphine (PtTFPP) and the reference dye of Coumarin 6 (C6) were encapsulated inside the hydrophobic environment of silane via the hydrolysis reaction, as the ratiometric sensing system, both of which can share the same excitation wavelength. In addition, the iron oxide nanoparticles (IONPs) with ultrasmall size were also employed as core together with PtTFPP and C6 molecules, and the composite was called as

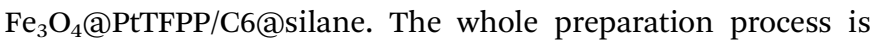
described in Fig. 1. The multifunction design holds the advantages of magnetic separation of cells and cellar ratiometric oxygen sensing. What's more, we first found the efficient energy transfer from C6 to PtTFPP with the excitation at $458 \mathrm{~nm}$, which shows higher luminescent intensity and much more harmless to the cells relative to that intrinsic excitation at UV area.

\section{Materials and methods}

\section{Materials}

The oxygen probe $\mathrm{Pt}(\mathrm{II})-m e s o$-tetra(pentafluorophenyl)porphine (PtTFPP), the reference dye Coumarin 6 (C6), trimethox$\mathrm{y}$ (octadecyl)silane, $\mathrm{FeCl}_{3} \cdot 6 \mathrm{H}_{2} \mathrm{O}, \mathrm{FeCl}_{2} \cdot 4 \mathrm{H}_{2} \mathrm{O}$, glucose, glucose oxidase and tetrahydrofuran (THF) 3-(4,5-dimethylthiazol-2-yl)2,15-diphenyltetrazolium bromide (MTT) assay were purchased from Sigma-Aldrich (http:/www.sigmaaldrich.com). All chemicals were used without further purification. Doubly distilled water was used in all experiments.

\section{Synthesis of magnetic $\mathrm{OA}-\mathrm{Fe}_{3} \mathrm{O}_{4} \mathrm{NPs}$}

Magnetic $\mathrm{OA}-\mathrm{Fe}_{3} \mathrm{O}_{4}$ NPs were synthesized following a recipe as below. Firstly, $\mathrm{FeCl}_{3} \cdot 6 \mathrm{H}_{2} \mathrm{O}(5.38 \mathrm{~g}$ ) was resolved in deionized water $(200 \mathrm{~mL})$ in three-necked flask for 10 min nitrogen gas protection. Then $\mathrm{FeCl}_{2} \cdot 4 \mathrm{H}_{2} \mathrm{O}(1.98 \mathrm{~g})$ was added into the former solution with the color changing to orange immediately. After $10 \mathrm{~min}$, ammonium hydroxide solution (25\%, $7 \mathrm{~mL}$ ) was injected into the three-necked flask with vigorous stirring, and the color of the mixture changed to black instantly. The solution was stirred for an additional 3 hours at room temperature and then washed with deionized water for three times. The black product was dissolved in $200 \mathrm{~mL}$ of deionized water with oleic acid (OA, $1.22 \mathrm{~g}$ ) dropwise added. The mixture was heated to $80^{\circ} \mathrm{C}$ for $30 \mathrm{~min}$ with stirring under a flow of nitrogen. The $\mathrm{OA}-\mathrm{Fe}_{3} \mathrm{O}_{4} \mathrm{NPs}$ were dissolved in hexane for further experiments.

\section{Synthesis of silane-modified $\mathrm{OA}-\mathrm{Fe}_{3} \mathrm{O}_{4} \mathrm{NPs}$ loading with $\mathrm{C6}$ and PtTFPP}

The $\mathrm{OA}-\mathrm{Fe}_{3} \mathrm{O}_{4}$ NPs $\left(5 \mathrm{mg} \mathrm{mL} \mathrm{m}^{-1}, 40 \mu \mathrm{L}\right)$, trimethoxy(octadecyl) silane $\left(7.5 \mathrm{mg} \mathrm{mL}^{-1}, 100 \mu \mathrm{L}\right)$, the reference dye Coumarin 6 (C6, $\left.1 \mathrm{mg} \mathrm{mL}{ }^{-1}, 50 \mu \mathrm{L}\right)$ and PtTFPP $\left(1 \mathrm{mg} \mathrm{mL}^{-1}, 60 \mu \mathrm{L}\right)$ were mixed in tetrahydrofuran (THF) under sonication. After 10 minutes, mixing solution was rapidly injected to $5 \mathrm{~mL}$ water $(\mathrm{pH} \approx 9$, adjusted by addition of ammonium hydroxide) in a conical flask for the hydrolyse process. Then the conical flask was put in a water bath at $30{ }^{\circ} \mathrm{C}$ for $4 \mathrm{~h}$, and the resolution was dialyzed for $24 \mathrm{~h}$ at room temperature. In the end, $\mathrm{Fe}_{3} \mathrm{O}_{4} @$ PtTFPP/ C6@silane NPs were finished.

\section{Cell culture}

The MCF-7 cells were purchased from Shanghai Institute for Biological Sciences Chinese Academy of Science, and were cultured in culture medium RPMI 1640 (Hyclone) supplemented with $10 \%$ fetal bovine serum (FBS, Clark) and $1 \%$ penicillin-streptomycin $\left(100 \mathrm{U} \mathrm{mL}^{-1}\right.$ penicillin and $100 \mathrm{~g} \mathrm{~mL}^{-1}$ streptomycin), in an incubator with $5 \% \mathrm{CO}_{2}$ and $100 \%$ humidity at $37^{\circ} \mathrm{C}$. Cells in the exponential phase of growth were used in all the experiments.

\section{Cytotoxicity assay}

For the in vitro cytotoxicity test, MCF-7 cells were cultured in RPMI-1640 medium containing 10\% fetal bovine serum (FBS) and $1 \%$ penicillin/streptomycin under $37{ }^{\circ} \mathrm{C}$ within $5 \% \mathrm{CO}_{2}$ atmosphere. 3-(4,5-Dimethylthiazol-2-yl)-2,15-diphenyltetrazolium bromide (MTT) assay was used to determine the cytotoxicity at various mass concentrations of samples. MCF-7 cells were seeded in 96-well plates at $1 \times 104$ per well and cultured for $24 \mathrm{~h}$. Then

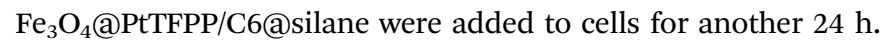
After adding $10 \mu \mathrm{L}$ of $5 \mathrm{mg} \mathrm{mL}^{-1}$ MTT solution for a further $4 \mathrm{~h}$ incubation $\left(37^{\circ} \mathrm{C}\right)$, the medium was carefully removed, and 150 $\mu \mathrm{L}$ of dimethyl sulfoxide was added. After 10-20 min dissolution, the absorbance at $490 \mathrm{~nm}$ was recorded using a microplate reader (Bio-Tek ELX800, USA).

\section{Femtosecond transient absorption setup}

The TA setup consisted of $400 \mathrm{~nm}$ pump pulses doubled from $800 \mathrm{~nm}$ laser pulses ( $\sim 100 \mathrm{fs}$ duration, $250 \mathrm{~Hz}$ repetition rate) 
generated from a mode-locked Ti: sapphire laser/amplifier system (Solstice, Spectra-Physics) and broadband white-light probe pulses generated from $2 \mathrm{~mm}$-thick deuterated water. The relative polarization of the pump and the probe beams were set to the magic angle. The TA data were collected by a fibercoupled spectra-meter connected to a computer. The group velocity dispersion of the transient spectra was compensated for using a chirp program. All the measurements were performed at room temperature. Pump-power dependent measurements were carried out. In the acceptable range, pump intensity independent dynamics were observed. ${ }^{35}$

\section{Results and discussion}

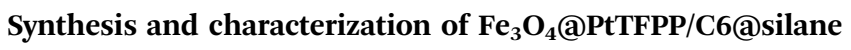 NPs}

The Scheme 1 shows the preparation process and cellar oxygen sensing application of composite $\mathrm{Fe}_{3} \mathrm{O}_{4} @$ PtTFPP/C6@silane NPs. PtTFPP is a famous oxygen probe, which is greatly sensitive to the concentration of oxygen. Upon $405 \mathrm{~nm}$ excitation, PtTFPP yields highly oxygen-sensitive red phosphorescence with a good quenching response. Thus, by detecting the intensity of the $652 \mathrm{~nm}$ wavelength, can be detected by spectrometer and visualized from CLSM. C6 serves as a reference probe since it can be co-excited under $405 \mathrm{~nm}$ wavelength while is not sensitive to $\mathrm{O}_{2}$. Amazingly, the co-loading of C6 can remarkably improve the luminescent intensity of PtTFPP at the wavelength of $652 \mathrm{~nm}$ under the highest excitation wavelength of $458 \mathrm{~nm}$ for $\mathrm{C} 6$, which is harmless for biological samples and efficient in the detection of oxygen. The inner magnetic $\mathrm{Fe}_{3} \mathrm{O}_{4}$ NPs offer the cell separation function, which is favorable for some certain cellular oxygen detention via magnetic navigation targeting to the tumor site or separation of circulating tumor cells in blood.

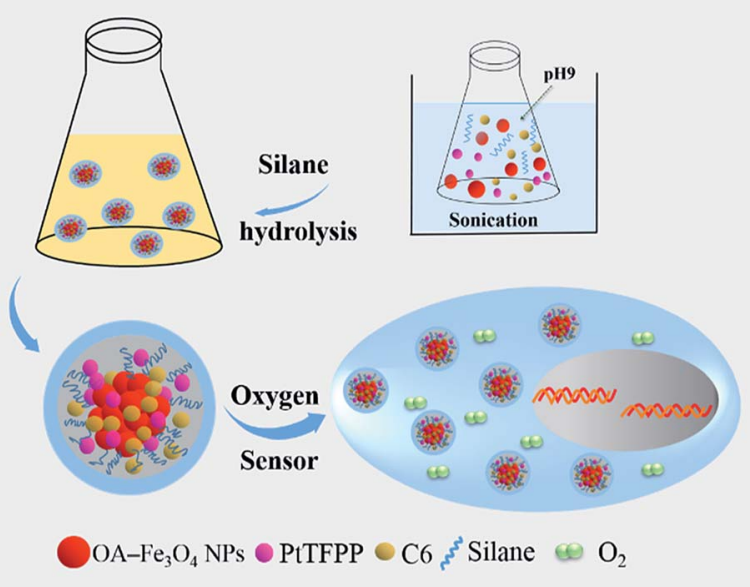

Scheme 1 Schematic representation of the synthesis of the $\mathrm{Fe}_{3}$ $\mathrm{O}_{4}$ aPtTFPP/C6@asilane.
The TEM image of $\mathrm{Fe}_{3} \mathrm{O}_{4}$ @PtTFPP/C6@silane in Fig. 1a shows basically spherical morphology after silane encapsulation with size of 120-150 nm. From the image of a single $\mathrm{Fe}_{3}$ $\mathrm{O}_{4}$ @PtTFPP/C6@silane particle in Fig. 1b, an aggregation of $\mathrm{Fe}_{3} \mathrm{O}_{4}$ NPs can be seen which happened in the hydrolysis process. The amphiphilic silane serves as coating layer and acts as the role of carrier, greatly improving the biocompatibility. Compared to other surface modification methods, this method is more simple and versatile without high temperature reaction.

The XRD pattern in Fig. 1c suggests the cubic crystalline structure of $\mathrm{Fe}_{3} \mathrm{O}_{4}$. From the UV-Vis absorption in Fig. 1d, the PtTFPP shows three bands at 400, 504 and $550 \mathrm{~nm}$, respectively. After being encapsulated inside the composites, the bands of PtTFPP also appear in the absorption spectra of $\mathrm{Fe}_{3} \mathrm{O}_{4}$ @PtTFPP@silane and $\mathrm{Fe}_{3} \mathrm{O}_{4} @ P t T F P P / C 6 @ s i l a n e ~ N P s$, confirming the successful preparation of the composites. The zeta potential of the resulting NPs are -34.6 (Fig. S1†), showing highly solubility and stability.

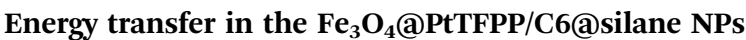

The excitation and emission spectra of pure PtTFPP, $\mathrm{Fe}_{3} \mathrm{O}_{4}$ @PtTFPP@silane, $\mathrm{Fe}_{3} \mathrm{O}_{4} @ \mathrm{C6}$ @silane and $\mathrm{Fe}_{3} \mathrm{O}_{4} @$ @tTFPP/ C6@silane are shown in Fig. 2a and b. Blue emission band centered at $510 \mathrm{~nm}$ belongs to $\mathrm{C} 6$ molecules, which can be excited by a wide band from 370 to 480 with the optimum wavelength of $458 \mathrm{~nm}$. $\mathrm{Fe}_{3} \mathrm{O}_{4} @ P$ PTFPP@silane NPs show the red emission at $652 \mathrm{~nm}$ with three excitation bands centered at 390,504 and $540 \mathrm{~nm}$, respectively. The two molecules can be coexcited by the wavelength from 400 to $410 \mathrm{~nm}$, since the C6 molecules play the role of reference probe. In this system, it is interesting that the excitation bands from $500 \mathrm{~nm}$ to $550 \mathrm{~nm}$ of PtTFPP molecules overlap with the emission band of C6 mole-

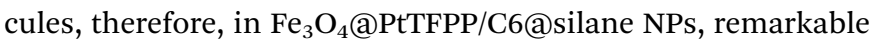
decrease of emission from C6 can be seen along with the obvious increase emission intensity of PtTFPP relative to the NPs with single molecule doping, which may be attributed to the energy transfer from C6 to PtTFPP molecules. Accordingly,

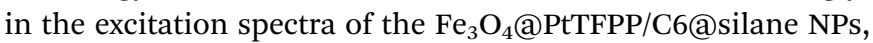
the excitation peak of $\mathrm{C6}$ also appears while monitoring the emission of PtTFPP at $652 \mathrm{~nm}$.
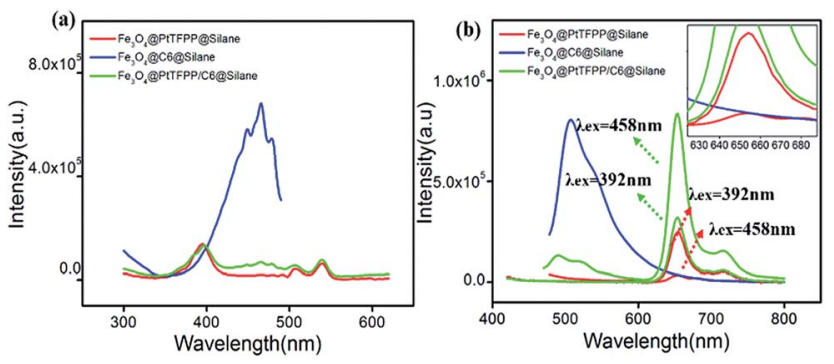

Fig. 2 (a) Excitation spectra of $\mathrm{Fe}_{3} \mathrm{O}_{4}$ @PtTFPPasilane, $\mathrm{Fe}_{3} \mathrm{O}_{4}$ (aC6@ silane and $\mathrm{Fe}_{3} \mathrm{O}_{4}$ @PtTFPP/C6 a silane NPs. (b) Emission spectra of 3 kinds of NPs $\left(\mathrm{Fe}_{3} \mathrm{O}_{4}\right.$ @PtTFPP@asilane, $\mathrm{Fe}_{3} \mathrm{O}_{4}$ aC6 asilane, $\mathrm{Fe}_{3} \mathrm{O}_{4} \mathrm{a}$ PtTFPP/C6(asilane) under 392 and $458 \mathrm{~nm}$ excitation. The inset shows the detail of the bottom area from $615 \mathrm{~nm}$ to $700 \mathrm{~nm}$. 
It is well known that long wavelength is more harmless to biological tissues than ultraviolet light. Therefore, $\mathrm{Fe}_{3} \mathrm{O}_{4}$ @PtTFPP/C6@silane NPs with excitation wavelength at $458 \mathrm{~nm}$ can afford better DO sensing application in cellar level rather than $392 \mathrm{~nm}$. Furthermore, based on the energy transfer from

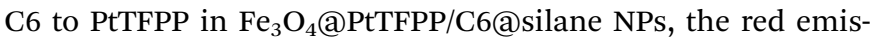
sion can be greatly enhanced. As shown in Fig. $2 \mathrm{~b}$, relative to the emission with the excitation of $392 \mathrm{~nm}$, the red emission intensity experience a 3.6-fold increase by exciting $\mathrm{C} 6$ molecules at $458 \mathrm{~nm}$ based on energy transfer process. However, $\mathrm{Fe}_{3}$ $\mathrm{O}_{4} @$ PtTFPP@silane NPs without C6 (red lines in Fig. 2b) show very low emission with the excitation of $458 \mathrm{~nm}$ relative to that of $392 \mathrm{~nm}$. Besides, compared with the emission of $\mathrm{Fe}_{3} \mathrm{O}_{4}$ @PtTFPP@silane NPs with the excitation of $458 \mathrm{~nm}$, the red emission intensity of $\mathrm{Fe}_{3} \mathrm{O}_{4} @$ @PtTFPP/C6@silane NPs shows a 20-fold increase by exciting $\mathrm{C} 6$ molecules based on energy transfer process. The results indicate the great contribution of C6 molecules in the luminescent property of the composite NPs.

Furthermore, we explored the ultrafast dynamics properties of the excited states using femtosecond broadband transient absorption (TA) spectroscopy. $\mathrm{Fe}_{3} \mathrm{O}_{4} @ \mathrm{C6} @$ silane and $\mathrm{Fe}_{3} \mathrm{O}_{4} @$ @PtTFPP/C6@silane NPs with same amount of C6 $11 \mathrm{mg} \mathrm{mL}{ }^{-1}$, $50 \mu \mathrm{L})$ but different amount of PtTFPP $\left(1 \mathrm{mg} \mathrm{mL}^{-1}, 60,80,100\right.$ $\mu \mathrm{L})$ were excited at $458 \mathrm{~nm}$, as shown in Fig. 3. The kinetics process of $\mathrm{C} 6$ at $500 \mathrm{~nm}$ was monitored. The lifetime value of $\mathrm{Fe}_{3} \mathrm{O}_{4} @$ C6@silane NPs is $1.9 \mathrm{~ns}$, while, with the increase amount of PtTFPP, the lifetime of C6 decreases accordingly. The corresponding lifetime of C6 are 1.51, 1.48, 1.10 ns by adding 60, 80, $100 \mu \mathrm{L}$ PtTFPP, respectively. This phenomenon proves the energy transfer from C6 to PtTFPP.

The small organic molecules exhibited the concentration dependent luminescent properties in the composites. The emission spectra of $\mathrm{Fe}_{3} \mathrm{O}_{4} @ P$ PTFPP@silane NPs with different concentration of PtTFPP $\left(1 \mathrm{mg} \mathrm{mL}{ }^{-1}, 20,40,60,80 \mu \mathrm{L}\right)$ under excitation of $458 \mathrm{~nm}$ are displayed in Fig. 4a. Among the four samples $\mathrm{Fe}_{3} \mathrm{O}_{4} @$ PtTFPP@silane NPs with $60 \mu \mathrm{L}\left(1 \mathrm{mg} \mathrm{mL} \mathrm{mL}^{-1}\right)$ PtTFPP show the highest emission intensity at $652 \mathrm{~nm}$. Based on the optimum concentration of PtTFPP, the concentration of C6 was further investigated by tuning the amount of C6 (1 mg

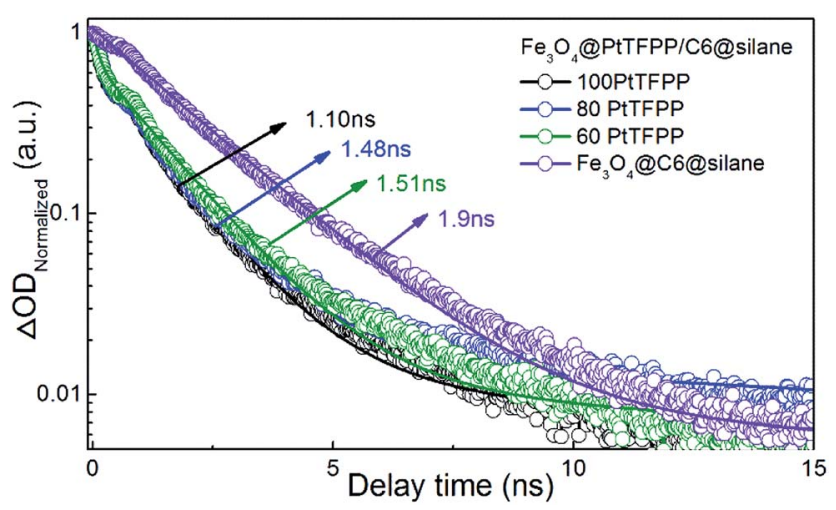

Fig. 3 Lifetime of $\mathrm{C} 6$ of 4 kinds of $\mathrm{NPs}\left(\mathrm{Fe}_{3} \mathrm{O}_{4} \mathrm{aC} 6\right.$ asilane, $\mathrm{Fe}_{3} \mathrm{O}_{4} \mathrm{a}$ PtTFPP/C6@silane (PtTFPP, $1 \mathrm{mg} \mathrm{mL}{ }^{-1}, 60 \mu \mathrm{L}$ ), $\mathrm{Fe}_{3} \mathrm{O}_{4}$ (aPtTFPP/ C6@asilane (PtTFPP, $1 \mathrm{mg} \mathrm{mL}{ }^{-1}, 80 \mu \mathrm{L}$ ), $\mathrm{Fe}_{3} \mathrm{O}_{4}$ @PtTFPP/C6@asilane (PtTFPP, $\left.1 \mathrm{mg} \mathrm{mL}^{-1}, 100 \mu \mathrm{L}\right)$ ).
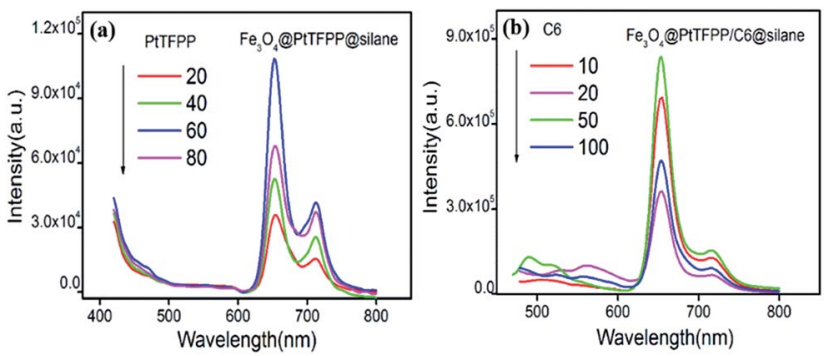

Fig. 4 (a) Emission spectra of $\mathrm{Fe}_{3} \mathrm{O}_{4}$ @PtTFPP(asilane NPs with different concentration of PtTFPP ( $\left.1 \mathrm{mg} \mathrm{mL}^{-1}, 20,40,60,80 \mu \mathrm{L}\right)$ under $458 \mathrm{~nm}$ excitation. (b) Emission spectra of $\mathrm{Fe}_{3} \mathrm{O}_{4}$ (aPtTFPP/C6 asilane NPs with different concentration of $\mathrm{C} 6\left(1 \mathrm{mg} \mathrm{mL}^{-1}, 10,20,50,100 \mu \mathrm{L}\right)$ under $458 \mathrm{~nm}$ excitation.

$\left.\mathrm{mL}^{-1}, 10,20,50,100 \mu \mathrm{L}\right)$. As displayed in the Fig. 4b, $\mathrm{Fe}_{3} \mathrm{O}_{4} @-$ PtTFPP/C6@silane NPs with $50 \mu \mathrm{L}\left(1 \mathrm{mg} \mathrm{mL}^{-1}\right) \mathrm{C} 6$ have the highest intensity at $652 \mathrm{~nm}$. Therefore, $50 \mu \mathrm{L}\left(1 \mathrm{mg} \mathrm{mL}^{-1}\right) \mathrm{C} 6$ was the proper concentration. In conclusion, $\mathrm{Fe}_{3} \mathrm{O}_{4} @ \mathrm{PtTFPP} /$ C6@silane NPs with C6 and PtTFPP concentration of $60 \mu \mathrm{L}$ $\left(1 \mathrm{mg} \mathrm{mL}^{-1}\right)$ and $50 \mu \mathrm{L}\left(1 \mathrm{mg} \mathrm{mL}^{-1}\right)$, respectively, were further used in the DO sensing.

\section{Extracellular oxygen sensitivity of the $\mathrm{Fe}_{3} \mathrm{O}_{4} @ P t T F P P /$ C6@silane NPs}

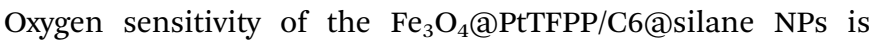
studied by flowing a gas mixture with various $\mathrm{N}_{2} / \mathrm{O}_{2}$ ratios. As is displayed in Fig. 5a, emission of C6 at 500 and the PtTFPP at $652 \mathrm{~nm}$ can be seen. After introducing different amount of dissolved oxygen (DO), emission of PtTFPP is quenched, whereas the emission of C6 keeps stable. By defining $R$ as the ratio of the emission intensity of PtTFPP (at $652 \mathrm{~nm}$ ) to that of
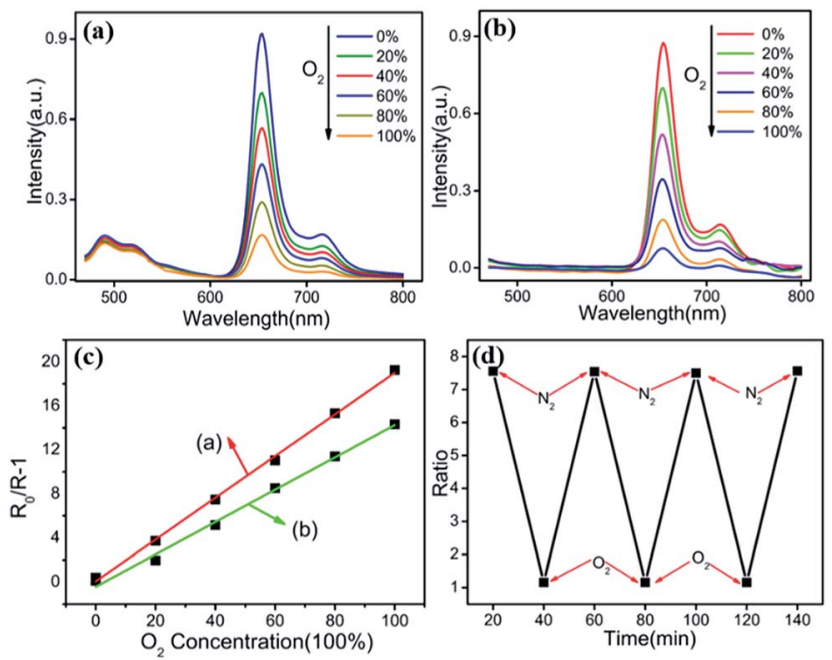

Fig. 5 (a and b) Ratiometric sensing with $\mathrm{Fe}_{3} \mathrm{O}_{4} @ \mathrm{aPtTFPP} / \mathrm{C} 6 \mathrm{asilane}$ and $\mathrm{Fe}_{3} \mathrm{O}_{4}$ (aPtTFPP@silane colloids, respectively. (c) Stern-Volmer plot of fluorescence intensity from (a and b). (d) Reversibility of $\mathrm{Fe}_{3}-$ $\mathrm{O}_{4}$ @PtTFPP/C6@silane NPs responding to dissolved oxygen. The fluorescence ratios are plotted versus the experimental time. 
C6 (at $500 \mathrm{~nm}$ ), the sensitivity of the nanosensors can be expressed by the overall quenching response to DO,

$$
Q=\left(R_{\mathrm{N}_{2}}-R_{\mathrm{O}_{2}}\right) / R_{\mathrm{N}_{2}}
$$

where $R_{\mathrm{N}_{2}}$ and $R_{\mathrm{O}_{2}}$ respectively represent the emission intensity ratios of the sensor in fully deoxygenated and fully oxygenated solutions. The as-obtained value of $Q$ for the hybrid sensing NPs is above $94 \%$.

In bulky solid state systems, the oxygen-quenching process usually is described by the nonlinear Stern-Volmer equation due to matrix heterogeneity effects. In a nanoscale system, however, the large surface/volume ratio as well as the shortened penetration depth of oxygen virtually disregards the microheterogeneity of the local environment, and oxygen quenching can be expressed, as in a homogeneous system, by the linear Stern-Volmer equation,

$$
R_{0} / R-1=K_{\mathrm{SV}}\left[\mathrm{O}_{2}\right]
$$

where $R_{0}$ is the emission intensity ratio in the absence of oxygen, $R$ as the ratio of a given oxygen concentration, $K_{\mathrm{SV}}$ as the SternVolmer quenching constant and $\left[\mathrm{O}_{2}\right]$ as the DO concentration. Fig. 4c depicts the Stern-Volmer plot of the emission intensity ratios of NPs versus DO. In the whole range of oxygen concentration, the results fit very well with a correlation coefficient of $>0.999$, showing important potential of practical oxygen sensing.

The oxygen sensitivity of the $\mathrm{Fe}_{3} \mathrm{O}_{4} @$ PtTFPP@silane NPs is plotted as line (b) in Fig. 5c the same as above. Compared the two plots calculated from (a) and (b), the slope of $\mathrm{Fe}_{3} \mathrm{O}_{4}$ @PtTFPP@silane NPs is lower than that of $\mathrm{Fe}_{3} \mathrm{O}_{4}$ @PtTFPP/ C6@silane NPs. The slope of line (a) is 0.9059, which is larger than that of line (b), whose slope is 0.7658 . As a result, adding C6 is much more beneficial to the oxygen sensitivity, because, in the composite, it serves as not only the reference probe, but also the sensitizer. Furthermore, $\mathrm{Fe}_{3} \mathrm{O}_{4} @$ PtTFPP/C6@silane also shows remarkable reversibility and obtains a complete recovery in each time, as depicted in Fig. 5d.

The physiological process of oxygen consuming was also imitated. With constant concentration of glucose $(8 \mathrm{mM})$, different concentration of glucose oxidase was added to the above solution to obtain an imitated hypoxia environment with various oxygen concentration. $\mathrm{Fe}_{3} \mathrm{O}_{4} @$ @PtTFPP/C6@silane NPs were added into the glucose solution in advance. The emission spectra of C6 and PtTFPP were tested before and after adding glucose oxidase, which could tune the oxygen consuming by catalyzing glucose degradation.

Firstly, glucose $(8 \mathrm{mM}, 100 \mu \mathrm{L})$ was added into a cuvette, containing $\mathrm{Fe}_{3} \mathrm{O}_{4} @$ PtTFPP/C6@silane colloids. After adding glucose oxidase $\left(1.4 \mathrm{mg} \mathrm{mL}^{-1}, 25 \mu \mathrm{L}\right)$ into the former solution, the emission spectrum was measured immediately with one minute interval. As the line 1 shows, the intensity increases suddenly as adding glucose oxidase and keeps stable. At this point, glucose oxidase reacted with glucose instantly, and oxygen consuming happened and then the red emission intensity of oxygen-sensitive PtTFPP improved. Since the oxygen from air re-dissolved into the solution, the reaction arrived at a balance as the plateau describes.

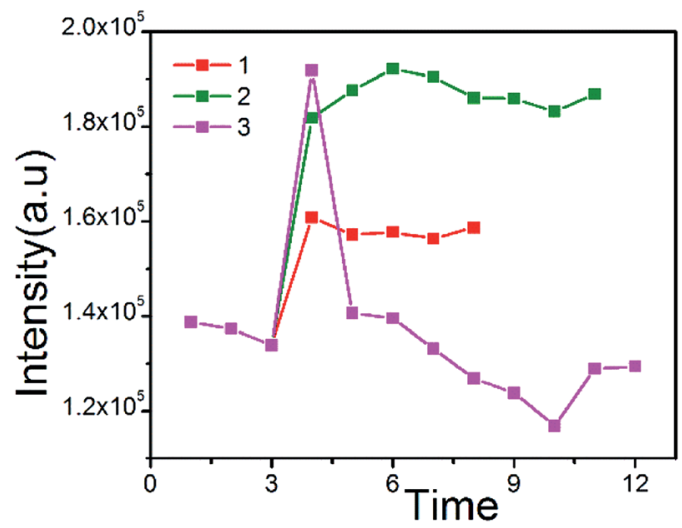

Fig. 6 The simplified physiological process of oxygen consuming was imitated through glucose $(8 \mathrm{mM}, 100 \mu \mathrm{L})$ and different amount of glucose oxidase, and DO sensing property was monitored with $\mathrm{Fe}_{3}{ }^{-}$ $\mathrm{O}_{4}$ (aPtTFPP/C6@asilane NPs.

Similarly, when adding increasing amount of glucose oxidase (1.4 $\mathrm{mg} \mathrm{mL}^{-1}, 50 \mu \mathrm{L}$ ), the line 2 was obtained, which showed the similar trend as the line 1 , because the more glucose oxidase were introduced, the less oxygen remained in the solution. When overdose glucose oxidase was added into the solution, as the line 3 showed, glucose could be consumed more quickly, which caused remarkable DO consumption. Therefore, the peak of line 3 was much higher than 1 and 2. However, in this situation, the line 3 also had an obvious decline after adding overdose glucose oxidase, since the glucose was totally decomposed. Therefore, the re-desolved oxygen from air cause the rapid decline of the red emission of PtTFPP. These experiments were repeated for many times and fully proved the oxygen sensitivity of the $\mathrm{Fe}_{3} \mathrm{O}_{4}$ @PtTFPP/C6@silane NPs by imitating the simplified physiological process of oxygen consuming (Fig. 6).

\section{Cytotoxic effect of the core-shell sensing NPs}

Before the intracellular oxygen sensing experiments, the potential cytotoxic effects are evaluated by using an MTT assay. The MTT assay is a colorimetric assay that measures the reduction of yellow 3-(4,5-dimethythiazol-2-yl)-2,5-diphenyltetrazolium bromide (MTT) by mitochondrial succinate dehydrogenase. MTT enters the cells and passes into the mitochondria where it is reduced to an insoluble colored (dark purple) formazan product. The cells are then solubilized with dimethyl sulfoxide and the released solubilised formazan reagent is measured spectrophotometrically. Therefore, it can be used to determine cytotoxicity of potential medicinal agents and toxic materials, since those agents would stimulate or inhibit cell viability and growth.

$\mathrm{Fe}_{3} \mathrm{O}_{4} @ P t T F P P / C 6 @ s i l a n e$ colloids with concentration range from 8 to $40 \mu \mathrm{g} \mathrm{mL}{ }^{-1}$ were incubated with MCF-7 cells for $12 \mathrm{~h}$, and then the mitochondria and metabolic activities of the cells were examined after exposure to the complex of MTT. As shown in Fig. 7, introducing NPs with concentration of $40 \mu \mathrm{g}$ $\mathrm{mL}^{-1}$ keeps the cell viability over $90 \%$, showing good biocompatibility and low cytotoxicity to the cells. 


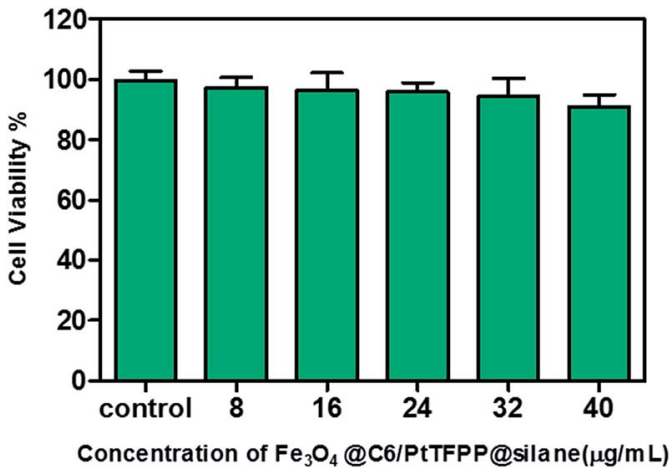

Fig. 7 MCF-7 cells viability determined by MTT assay. No significant difference between control and test groups is observed.

\section{Intracellular oxygen sensitivity of the $\mathrm{Fe}_{3} \mathrm{O}_{4} @ P t T F P P /$} C6@silane NPs

Laser confocal scanning microscopy (LCSM) was employed here to investigate the ratiometric sensing NPs inside MCF-7 cells, as shown in Fig. S3. $\dagger$ As above mentioned, the fluorescence of the reference C6 (Fig. S3a $\dagger$ ) and the probe PtTFPP (Fig. S3b $\dagger$ ) were recorded by the green $(475-550 \mathrm{~nm})$ and red $(620-680 \mathrm{~nm})$ channels, respectively, under the same excitation of $458 \mathrm{~nm}$ laser, which is the standard configuration laser of LCSM. The dual fluorescence property suggests that intracellular oxygen sensing with the ratiometric nanosensors is possible.

To investigate the in vitro hypoxic response of $\mathrm{Fe}_{3} \mathrm{O}_{4}$ @PtTFPP/C6@silane NPs, the MCF-7 cells were incubated with NPs $\left(40 \mu \mathrm{g} \mathrm{mL} \mathrm{m}^{-1}\right)$ for $24 \mathrm{~h}$. Before oxygen sensing, glucose $(8 \mathrm{mM}, 100 \mu \mathrm{L}$ ) was pumped into the sealed confocal dish. The initial DO concentration was measured by the green and red emission signal. Then glucose oxidase $\left(1.4 \mathrm{mg} \mathrm{mL}^{-1}, 50 \mu \mathrm{L}\right)$ was added into the dish rapidly. The signals from both channels were monitored and the ratiometric gray intensity of the same point on the images were calculated. The images were captured every 10 seconds in 12 minutes after the introduction of oxidase. The gray intensity of signal was obtained from a selected area as the circle present.

Firstly, the correlation between red emission of PtTFPP and DO in cells was investigated. As the plot in Fig. 8a shows, red signal increases after the adding of glucose oxidase, due to the consumption of the DO inside the cells. The corresponding images of first and highest signal point (at 7 minute) from the red channel also indicate the remarkable improvement in signal intensity and resolution. At the highest point, consumption and re-dissolve of the oxygen come to the balance, and after that the signal decreases.

After the involvement of the stable green signal from C6 channel, the ratiometric fluorescence sensing can be achieved as the plot shows in Fig. 8b. Though the fluctuate of the gray intensity of the images is hard to avoid in the CLSM system, in this case, the ratiometric intensity between green and red channels shows more linear property relative to that from the single PtTFPP sensing method. Besides, ratiometric fluorescence sensing method also can bring an obvious improvement in sensitivity. In detail, at the beginning, the green fluorescence
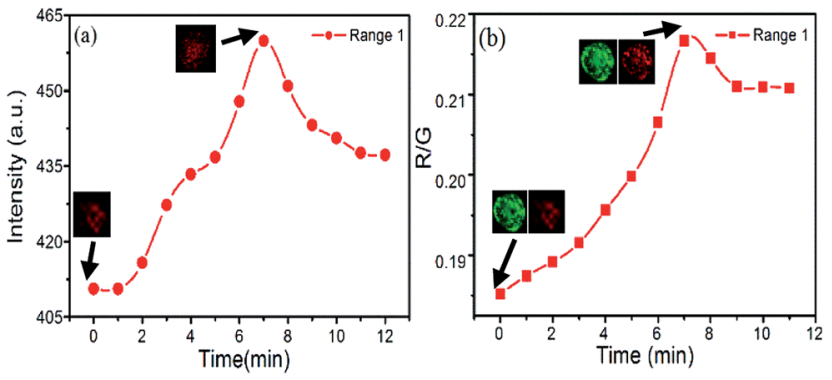

Fig. 8 (a) The red fluorescence emission intensity of $\mathrm{Fe}_{3} \mathrm{O}_{4}$ @PtTFPP/ C6 asilane was plotted accompanied with experimental time, after adding glucose oxidase $\left(1.4 \mathrm{mg} \mathrm{mL}^{-1}, 50 \mu \mathrm{L}\right)$ into the dish. The insets were the corresponding areas. (b) The ratio of red fluorescence and green fluorescence $(R / G)$ was plotted accompanied with experimental time after adding glucose oxidase $\left(1.4 \mathrm{mg} \mathrm{mL}^{-1}, 50 \mu \mathrm{L}\right)$ into the dish. The insets were the corresponding areas.

intensity from C6 is 2096.869 and the red fluorescence intensity from PtTFPP is 388.332. After 7 minutes, the maximum fluorescence intensity of both channels was achieved, which are 2275.784 and 480.1815 for red and green channels, respectively. By normalization of the green signal, the red signal behave a $14 \%$ increase. Also, the images corresponding to the first and highest points also support the signal variation. Therefore, though both the methods can be employed for the DO sensing, ratiometric fluorescence sensing shows better stability and sensitivity.

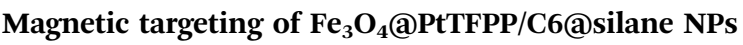

The cellar oxygen sensing is important in the tumor site or circulating tumor cells in blood, which are featured with hypoxia. Therefore, if magnetic navigation function can be integrated to the NPs, this multifunctional composites can be found more practical applications in clinic. In this work, the cell

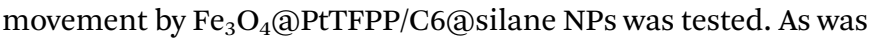
shown in Fig. 9, a magnet was set near a cell culture dish with
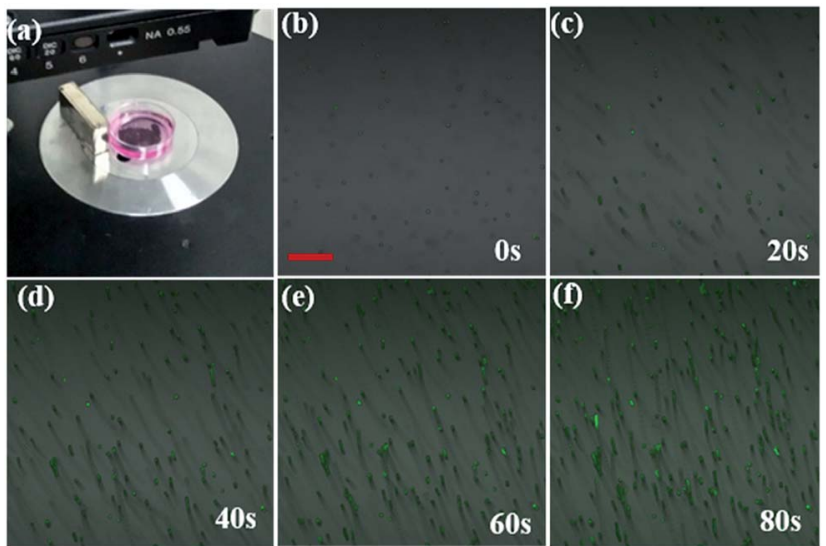

Fig. 9 MCF-7 cells intubated with $\mathrm{Fe}_{3} \mathrm{O}_{4} @$ PtTFPP/C6@ silane and then attracted to the lip of a Petri dish when the magnet was setting (a). (b) To (f) show the path and direction of the cells incubated with $\mathrm{Fe}_{3}-$ $\mathrm{O}_{4}$ @PtTFPP/C6@silane NPs at different time by overlaying pictures. The scale bar is $200 \mu \mathrm{m}$. 
MCF-7 cells incubated with $\mathrm{Fe}_{3} \mathrm{O}_{4}$ @PtTFPP/C6@silane. After that, MCF-7 cells started to move along the magnetic field direction and the process was observed by CLSM. It can be seen that the movement traces could be described by pictures overlaid at 0,20,40,60 and $80 \mathrm{~s}$, indicating the efficient magnetic separation property. In addition, all the movements was monitored with green channel by the signal from C6. Therefore, the moving green cells suggest the in vivo applications with the imaging and magnetic functions, as well as the DO sensing property. The cell movement experiments under the CLSM was also carried using bright-field channel, and the moving process was monitored as a Video (ESI $\dagger$ ). It is worthy to be mentioned here that the magnetic resonance imaging function can also be developed base on these $\mathrm{Fe}_{3} \mathrm{O}_{4} @$ PtTFPP/C6@silane composite NPs.

\section{Conclusions}

We have developed the composite $\mathrm{Fe}_{3} \mathrm{O}_{4} @ P t T F P P / C 6 @ s i l a n e$ NPs, which are suitable candidates with multifunctions of ratiometric fluorescence oxygen sensing, imaging and magnetic separation. The silane modification makes the composites stable and biocompatible. The efficient energy transfer from C6 to PtTFPP was proved, which greatly improve the DO sensing sensitivity and stability in imitation environment and in vitro experiments. Since C6 is not sensitive to oxygen, ratio metric emissions of C6 and PtTFPP can be employed here for precisely monitoring of oxygen concentration. The integration of magnetic property to the NPs, the composite with multifunction possess great potential in DO sensing related medical applications.

\section{Acknowledgements}

This work was supported by the National Key Research and Development Program (2016YFC0207101), Major State Basic Research Development Program of China (973 Program) (No. 2014CB643506), the program of Chang Jiang Scholars and Innovative Research Team in University (No. IRT13018) and the National Natural Science Foundation of China (Grant no. 11374127, 11304118, 81301289, 21403084 and 11674127) and National University Student Innovation Program (2016A51168).

\section{Notes and references}

1 T. Acker and H. Acker, J. Exp. Biol., 2004, 207, 3171.

2 J. Lopez-Barneo, R. Pardal and P. Ortega-Saenz, Annu. Rev. Physiol., 2001, 63, 259.

3 E. Ikeda, Pathol. Int., 2005, 55, 603.

4 R. Y. Zhang, R. R. Xing, T. F. Jiao, K. Ma, C. J. Chen, G. H. Ma and X. H. Yan, ACS Appl. Mater. Interfaces, 2016, 8, 13262.

5 X. N. Zhao, K. Ma, T. F. Jiao, R. R. Xing, X. L. Ma, J. Hu, H. Huang, L. X. Zhang and X. H. Yan, Sci. Rep., 2017, 7, 44076.

6 Y. M. Liu, K. Ma, T. F. Jiao, R. R. Xing, G. Z. Shen and X. H. Yan, Sci. Rep., 2017, 7, 42978.
7 R. R. Xing, T. F. Jiao, Y. M. Liu, K. Ma, Q. L. Zou, G. H. Ma and X. H. Yan, Polymers, 2016, 8, 181.

8 R. T. Xing, K. Liu, T. F. Jiao, N. Zhang, K. Ma, R. Y. Zhang, Q. L. Zou, G. H. Ma and X. H. Yan, Adv. Mater., 2016, 28, 3669-3676.

9 L. Galluzzi, E. Morselli, O. Kepp, I. Vitale, A. Rigoni, E. Vacchelli, M. Michaud, H. Zischka, M. Castedo and G. Kroemer, Mol. Aspects Med., 2010, 31, 1.

10 G. Kroemer and J. Pouyssegur, Cancer Cell, 2008, 13, 472.

11 F. Giacco and M. Brownlee, Circ. Res., 2010, 107, 1058.

12 J. H. W. Distler, R. H. Wenger, M. Gassmann, M. Kurowska, A. Hirth, S. Gay and O. Distler, Arthritis Rheum., 2004, 50, 10. 13 J. N. Demas and B. A. Degraff, Anal. Chem., 1991, 63, 829A. 14 C. Preininger, I. Klimant and O. S. Wolfbeis, Anal. Chem., 1994, 66, 1841.

15 Z. Rosenzweig and R. Kopelman, Anal. Chem., 1995, 67, 2650. 16 C. McDonagh, B. D. MacCraith and A. K. McEvoy, Anal. Chem., 1998, 70, 45.

17 C. McDonagh, C. S. Burke and B. D. MacCraith, Chem. Rev., 2008, 108, 400.

18 F. Peng, Y. Y. Su, Y. L. Zhong, C. H. Fan, S. T. Lee and Y. He, Acc. Chem. Res., 2014, 47, 612.

19 X. D. Wang and O. S. Wolfbeis, Chem. Soc. Rev., 2014, 43, 3666. 20 Y. E. K. Lee, E. E. Ulbrich, G. Kim, H. Hah, C. Strollo, W. Fan, R. Gurjar, S. Koo and R. Kopelman, Anal. Chem., 2010, 82, 8446. 21 Y. Q. Gong, B. Yu, W. Yang and X. L. Zhang, Biosens. Bioelectron., 2016, 79, 822.

22 A. A. Khan, G. D. Vigil, Y. D. Zhang, S. K. Fullerton-Shirey and S. S. Howard, Opt. Mater., 2017, 7, 1066.

23 T. Yoshihara, Y. Hirakawa, M. Hosaka, M. Nangaku and S. Tobita, J. Photochem. Photobiol., C, 2017, 30, 71.

24 E. R. Carraway, J. N. Demas, B. A. Degraff and J. R. Bacon, Anal. Chem., 1991, 63, 337.

25 A. Mills and A. Lepre, Anal. Chem., 1997, 69, 4653.

26 M. S. Tremblay, M. Halim and D. Sames, J. Am. Chem. Soc., 2007, 129, 7570.

27 X. D. Wang, X. Chen, Z. X. Xie and X. R. Wang, Angew. Chem., Int. Ed., 2008, 47, 7450.

28 X. D. Wang, T. Y. Zhou, X. H. Song, Y. Jiang, C. J. Yang and X. Chen, J. Mater. Chem., 2011, 21, 17651.

29 X. D. Wang, H. H. Gorris, J. A. Stolwijk, R. J. Meier, D. B. M. Groegel, J. Wegener and O. S. Wolfbeis, Chem. Sci., 2011, 2, 901.

30 X. H. Wang, H. S. Peng, H. Ding, F. T. You, S. H. Huang, F. Teng, B. Dong and H. W. Song, J. Mater. Chem., 2012, 22, 16066.

31 S. S. Lu, X. Wei, J. L. Zhang, Y. Y. Chen, L. Lei, Q. H. Yao, Y. Q. Jiang, Y. R. Wang and X. Chen, Biosens. Bioelectron., 2016, 86, 176.

32 K. A. Van Houten, D. C. Heath, C. A. Barringer, A. L. Rheingold and R. S. Pilato, Inorg. Chem., 1998, 37, 4647.

33 C. F. Wu, B. Bull, K. Christensen and J. McNeill, Angew. Chem., Int. Ed., 2009, 48, 2741.

34 X. H. Wang, H. S. Peng, L. Yang, F. T. You, F. Teng, L. L. Hou and O. S. Wolfbeis, Angew. Chem., Int. Ed., 2014, 53, 1.

35 J. L. Du, H. Y. Wang, L. Wang, S. J. Zhu, Y. B. Song, B. Yang and H. B. Sun, J. Mater. Chem. C, 2016, 4, 2235. 